Brit. J. vener. Dis. (1966), 42, 213.

\title{
CORRESPONDENCE
}

To the Editor,

\section{British Journal of Venereal Diseases}

SIR, I recently reported a case of congenital syphilis in a man aged 22 years with aortic incompetence which was thought to be syphilitic in origin (Brit.J.vener. Dis., 1965, 41, 149).

The patient died suddenly in September, 1965, approximately 16 months after the onset of his symptoms. The post mortem report stated that the heart weighed $400 \mathrm{~g}$. There was left ventricular dilatation. The aortic valve showed marked thickening, the free edge was cord-like. There was white thickening of the aortic intima covering an area of approximately $2 \mathrm{~cm}$. above the valve. The ostium of the right coronary artery was completely occluded. The left coronary artery was normal. The other valves were normal. The myocardium showed no abnormality and the pericardium appeared healthy. The brain showed no organic disease and the meninges were not thickened. The pathological diagnosis was:

(1) Coronary occlusion;

(2) Syphilitic aortitis.

This additional information may be of interest to your readers.

Yours faithfully

R. J. WHITE

Croydon Chest Clinic,

MAYDAY HOSPITAL,

MAYDay Road,

THORNTON Heath, SuRRey

June 10, 1966

\section{BOOK REVIEWS}

Basic Dermatology. By P. J. Hare. 1966. Pp. 198, 61 figs. Lewis, London. (42s.)

Probably the only justification for the publication of a new medical text-book, as opposed to the revision and re-issue of old and tried favourites, is a new approach to the subject. In giving dermatology a new look Dr Hare divides his subject matter into three distinct parts. In Part I he presents in a pleasant, interesting, and narrative style a broad view of dermatology, including information on many "small-print" diseases not usually found in short text-books. Part II, in similar style with end of chapter summaries, deals with differential diagnosis and discusses some of the diseases in more detail, which involves some repetition of Part I. The comparatively short Part III, mostly written in note form with an alphabetic list of diseases, is concerned with treatment and, although this covers a wide field, it is somewhat reminiscent of the therapeutic index in a pharmaceutical manufacturer's diary.

The volume is profusely illustrated and well indexed. Each of the 61 figures listed consists of a group of related illustrations, and there are in all some 280 black-and-white photographs, mostly of excellent quality and detail. Very little histological description is given and, surprisingly enough, this presentation of basic dermatology does not seem to be any the worse for the omission of the usual considerations of normal anatomy, physiology, and routine pathology.

"Basic Dermatology" is a meticulously produced and readable book and should prove of interest to those wanting a general picture of skin disorders. It might be of particular value to venereologists who would not find the scanty descriptions of the skin manifestations of syphilis any disadvantage. Benjamin Schwartz

Venereal Diseases. By R. S. Morton. 1966. Pp. 185, illus. Penguin Books Ltd., London. (3s. $6 d$.)

Venereal diseases are as much a social as a medical problem and the general public is still largely ignorant or misinformed about them. Enlightenment is spreading and the problems which the sexuallytransmitted diseases present can now be openly discussed on television and in other mass media of information. This is all to the good, as the creation of an informed public opinion would be a powerful ally to merely medical means of combating these infections. For this, however, the public must have access to the facts, both medical and social, about venereal infections, presented dispassionately and in a form which the intelligent layman can understand. Dr Morton has provided just this.

A surprising amount of information is presented very clearly and in a small compass about the history, manifestations, and incidence of the sexually transmitted diseases and on the social factors which so largely influence their prevalence in our society to-day. It should be of great help as a source of factual information to social workers, school teachers, and those interested in health education and youth organizations. Both medical students and nurses will find it a useful supplement to a didactic textbook because of the illustrations it gives of the interplay of social factors affecting the prevalence of disease in a community. The author is to be congratulated on this book; it is to be hoped that it will be widely read.

A.E.W. 